\title{
Cuando el Estado y la sociedad confluyen: la construcción de la política territorial en San Martín (2002-2018)
}

\author{
María Claudia Augusto*
}

\footnotetext{
* Licenciada en Ciencia Política y Gobierno por la Pontificia Universidad Católica del Perú (PUCP). Ha sido asistente de investigación en el Centro de Investigación de la Universidad del Pacífico y actualmente es predocente de la especialidad de Ciencia Política de la PUCP.Correo electrónico: mcaugusto@pucp.pe
}

Fecha de recepción: 26/06/2019. Fecha de aceptación: 08/08/2019 


\section{Cuando el Estado y la sociedad confluyen: La construcción de la política territorial en San Martín (2002-2018)}

\section{RESUMEN}

En 2002, el Perú retomó el proceso de descentralización en base a departamental, asignando funciones a los nuevos gobiernos regionales. A la fecha, el proceso ha mostrado resultados heterogéneos. La mayoría de gobiernos exhibe problemas para cumplir la ley en el territorio. Pese a ello, es posible identificar experiencias positivas. Este artículo se centra en el estudio de la política territorial y ambiental en San Martín, que pasó de ser la región más deforestada del país para convertirse en un modelo en la implementación de políticas a nivel nacional. Para responder esta pregunta nos centramos en dos variables. Por un lado, resaltamos la importancia de los vínculos entre el Estado y sociedad para el fortalecimiento de la capacidad estatal y por otro, el liderazgo político, clave para priorizar y posicionar sus propuestas. En ese sentido, el artículo resalta la importancia que tiene la demanda local para fomentar el fortalecimiento y la continuidad de las políticas en el tiempo.

Palabras clave: capacidad estatal, sociedad civil, liderazgo político, política territorial, San Martín.

When State and society meet:The land-use planning policy in San Martin (20022018)

\section{Abstract}

In 2002, Peru launched a decentralization process that assigned functions to 25 new regional governments. The reform has exhibited dissimilar results. The majority of subnational governments experience challenges to enforce the law in their territories. Despite that, it is possible to identify positive experiences. This article focuses in the study of territorial and environmental policies in San Martín, a region that used to be the most deforested region in the country and that has become a role model for the implementation of conservation policies. To answer this question, we focus in two variables. On the one hand, we show the importance of state-society linkages in the strengthen of state capacity and, on the other, the positive effect of political leadership in the prioritization of policies. The article, then, aims to emphasize how local demand can promote, enforce and guarantee the continuity of policies over time.

Keywords: state capacity, civil society, political leadership, territorial management, San Martín. 


\section{INTRODUCCIÓN}

En una visita a Cajamarca, donde promulgó la Ley de Bases de Descentralización, Alejandro Toledo declaró: «No habrá marcha atrás, ha llegado el momento de las regiones». El tiempo le daría la razón. Diecisiete años después - luego de un boom económico, cinco presidentes y cuatro procesos electorales—, la descentralización ha persistido. Pero, en un Estado históricamente débil, ha creado más de un desafío.

En el Perú, la descentralización es un ejemplo de cambio institucional constante (Levitsky y Murillo, 2014). Propuesta en la década de 1970, implementada en la de 1980, paralizada en la de 1990 y retomada a inicios de siglo, ha recorrido un largo camino. Tras la transición democrática, fue vista como una medida capaz de fortalecer al régimen. Sin embargo, la aprobación de otras reformas simultáneas mostraría las deficiencias de un diseño más pensado desde lo político que desde lo técnico (Muñoz, 2018). El fracaso del referéndum de 2005, aquel que planteaba las macrorregiones, agudizó el panorama.

En la actualidad, los resultados han sido variados. La creación de un nuevo nivel de gobierno arrasó a partidos ya débiles frente a la presencia de organizaciones regionales (Vergara, 2011). En el territorio, algunas regiones han hecho gala de baja capacidad, replicando problemas del nivel central, o de un desinterés crónico de hacer cumplir la ley. Y aunque los ejemplos de zonas marrones (O’Donnell, 1993) abundan, otras regiones sí han mostrado ser exitosas en cumplir sus funcione, lo que nos lleva a preguntarnos, ¿qué determina esta diferencia?

El siguiente artículo analiza la implementación de la política territorial en San Martín, una región de la Amazonía peruana. Como veremos, la descentralización fue vista como una oportunidad para impulsar una agenda regional marcada por un pasado particular. De ser la región más deforestada del país ha pasado a ser un ejemplo de conservación. En efecto, San Martín ha sido pionera en la implementación de políticas de participación ciudadana, gestión territorial, conservación, entre otros. Y, tras cuatro períodos regionales, resulta difícil creer que esta situación cambie en el corto plazo.

En ese sentido, se resaltan dos factores. De un lado, la articulación entre el Estado y la sociedad civil. Desde la década de 1980, la región cuenta con grupos organizados que promueven la conservación ambiental y que han encontrado un aliado en la gestión regional, impulsando la continuidad de las políticas en el tiempo. De otro, el liderazgo político. Este ha resultado importante para fortalecer la capacidad estatal de las agencias encargadas y consolidar una visión regional. Si bien el caso dista de ser perfecto, hay avances muy importantes.

El estudio del caso resulta interesante por tres motivos. Primero, el ejemplo de San Martín contrasta con una visión nacional que ha priorizado la explotación de recursos naturales por encima de la sostenibilidad ambiental. Segundo, a diferencia de 
lo ocurrido en la sierra, la intervención en el territorio amazónico ha sido tardío y desordenado y ha planteado mayores retos para sus autoridades regionales. Finalmente, la experiencia en esta región ha sido llevada a otros espacios sin el mismo éxito. Entender su particularidad, resulta entonces, importante. Cabe agregar, que este trabajo parte de la tesis de licenciatura realizada por la autora (Augusto, 2017) y recoge la revisión de hnormativa regional, la consulta a fuentes secundarias y la realización de 23 entrevistas semiestructuradas a actores del proceso.

\section{DisCUSIÓN TEÓRICA}

Desde la década de 1980, el retorno del Estado como centro de estudio ha llevado a indagar las razones que explican que algunos Estados sean más fuertes que otros. Las reformas descentralistas, emprendidas en países europeos y latinoamericanos, han añadido otras interrogantes. El interés por entender la variación dentro de áreas del Estado es cada vez más notorio y ha sido respondido de diversas formas.

Para fines de este trabajo, entendemos la capacidad como la capacidad institucional del Estado central para penetrar su territorio o implementar sus decisiones (Mann, 1984). Esto implica establecer objetivos que puedan ser llevados a cabo. Sin embargo, en países en desarrollo, donde el alcance territorial dista de ser homogéneo, la brecha de implementación entre lo que se espera y realiza suele ser alta (Grindle, 2009). El mundo no está hecho de buenas voluntades.

Diversos autores han ahondado en factores que fortalecen o inhiben la capacidad estatal. Una primera línea ha priorizado la dimensión organizacional. La existencia de elementos como un marco legal funcional, recursos económicos o especialmente, de una burocracia weberiana, serían «inputs» potenciales para alcanzar el objetivo (Bersh, Praça y Taylor, 2017). El acento en la burocracia es clave. Incluso, para algunos autores, es vital centrarse en la calidad de la burocracia «independientemente de si es desplegada o para qué fin» (Centeno, Kohli, Yashar y Mistree, 2017, p. 6).

La evidencia sugiere que algunas áreas son más atractivas que otras. Agencias diplomáticas o económicas suelen contar con mayor capacidad estatal frente a otras de temas sociales o ambientales (Dargent, 2008; McAllister, 2008). Sin embargo, ¿qué explica que aun pese a las limitaciones, algunas agencias alcancen un buen desempeño?

Para el siguiente trabajo, priorizamos variables sociales y políticas. Sabemos que la mayoría de países en desarrollo suele adolecer de un mismo diagnóstico: burocracias poco estables o informales, reglas de juego en constante cambio, presupuestos limitados o problemas de corrupción. Sin embargo, la relación con actores sociales puede generar una demanda que lleve a una mejor actuación. El Estado establece un vínculo relacional, en la medida en que afecta y es afectado por los actores sociales con los que 
se vincula y, por tanto, puede resultar en mayor efectividad (Migdal, Kohli y Shue, 1994). En la línea de North (1995), las organizaciones ayudan a explicar la continuidad de las instituciones.

Dentro de esta relación, los actores sociales inciden de forma distinta. Primero, pueden ser una fuente de legitimidad. La acción estatal puede encontrar respaldo en actores sociales en juego o crear nuevas bases de apoyo. Veamos algunos ejemplos. Para actores empresariales, normas que alteran la distribución del poder en el corto plazo, pueden ser garantía de predictibilidad y ventaja frente a competidores en el futuro (Pierson, 1993), comprometiendo su apoyo para un despliegue positivo. De forma similar, organizaciones de base pueden emplear repertorios de movilización para fomentar o garantizar la acción estatal. En temas ambientales, por ejemplo, los grupos ambientalistas son conocidos por generar incidencia a través de protestas, procesos legales o pedidos de mayor enforcement (Amengual, 2016). Finalmente, actores internacionales pueden optar por apoyar o financiar políticas que sean congruentes con sus agendas, abriendo una ventana de oportunidad para el fortalecimiento estatal. Como sugiere Dargent (2014), los desafíos o intereses de la agenda internacional pueden ser aprovechados por la burocracia doméstica, llevando a cambios grandes o sutiles.

Segundo, pueden participar del ciclo de políticas públicas, abaratando los costos de intervención. Es decir, los actores sociales no solo muestran un respaldo simbólico, sino que pueden tener una participación activa en el diseño e implementación de políticas de la mano de la burocracia. El clásico texto de Evans (1996), por ejemplo, reveló la importancia de la comunicación entre el sector privado y los funcionarios de países del sudeste asiático, para el desarrollo económico ${ }^{1}$. Sin embargo, esto también es aplicable a Estados débiles o clientelares. Por ejemplo, Matthew Amengual (2016) muestra que la alianza con los beneficiarios incidió de forma positiva en el enforcement de políticas laborales y ambientales, a través de recursos materiales y del ejercicio de fiscalización. Nuevamente, ante la existencia de un interés compartido con la sociedad, el Estado pude hacer uso de estrategias formales e informales (Ha y Kang, 2011) para mejorar su efectividad.

En la región, existen otras experiencias positivas. Rich, Mayka y Montero (2019) muestran que más allá de las políticas neoliberales, el último proceso democratizador en América Latina generó una ampliación de la ciudadanía. Estos nuevos actores participaron de nuevos canales de participación, alejados de la política representativa tradicional, interviniendo en áreas de política novedosas como el medio ambiente (véase también, Abers y Keck (2009). Estos procesos, comunes a toda la región,

\footnotetext{
1 Evans (1996) emplea el concepto de autonomía enraizada, para lo cual se precisa de la existencia de una burocracia weberiana.
} 
han permitido espacios de incidencia inéditos entre la sociedad y el Poder Ejecutivo, Legislativo y Judicial.

Uno de los principales cambios es la aparición de «burócratas activistas» (Abers, 2019; Rich, 2019) caracterizados por impulsar espacios participativos, mantener relaciones estrechas con la sociedad civil e impulsar políticas que fortalezcan a sus aliados, así como la aparición de ONG de profesionales, dispuestos a negociar con el Estado. Políticas de presupuesto participativo, desarrollo concertado o foros de discusión son ejemplo de un enfoque que valora la participación de ciudadanos y expertos para recoger información o aplicar la ley. Aunque estos espacios no conducen necesariamente a resultados efectivos, como muestran distintos autores, las coaliciones entre el Estado y la sociedad civil son un activo importante para la gestión pública.

Finalmente, el apoyo puede provenir de espacios más especializados. La literatura sobre comunidades epistémicas, muestra a expertos que inciden desde dentro o fuera del Estado con agendas que buscan el fortalecimiento en áreas de política ${ }^{2}$. La construcción de la política ambiental, por ejemplo, tuvo su origen en grupos profesionales ambientalistas. Esto no es propio de Perú, en el sector estatal es común ver a comunidades de profesionales articulados a nivel internacional (Haas, 1992) y con una agenda clara en la esfera doméstica.

No obstante, en Estados débiles, este vínculo debe ser tomado con sumo cuidado. Autores como Dargent y Urteaga (2016), sugieren que la existencia de una debilidad previa es una desventaja frente a fuerzas sociales que pueden sobreponerse rápidamente al Estado ante el intento de ser reguladas. En suma, «un Estado seguirá siendo débil en buena parte porque ya es débil, porque no cuenta con los recursos necesarios para superar este momento inicial» (2016, p. 177). Pese a ello, se registran experiencias positivas a nivel subnacional para el caso peruano (véase Augusto, Dargent y Rousseau, 2017).

Nuestra segunda explicación se centra en variables políticas. Las autoridades en cargo resultan clave para explicar por qué en algunas agencias se aumentan o restringen recursos, se impulsan o postergan agendas o se activan y desmantelan agencias. Al fin y al cabo, los políticos tienen prioridades que se reflejan en decisiones de política. Como muestra Grindle (2004), dentro del escenario dinámico de las políticas públicas, la arena política es clave para definir prioridades, características y estrategias en la aplicación de políticas. Los intereses de las autoridades pueden llevar a priorizar una u otra, aun cuando se enfrenten a obstáculos institucionales. Dentro de este juego, otra variable clave es la legitimidad. Para Carpenter (2001),

\footnotetext{
Al hablar de comunidades epistémicas, seguimos la definición de Haas quien plantea que estas se encuentran formadas por profesionales reconocidos que comparten una visión sobre materias específicas (Haas, 1992).
} 
aunque aplicado a burócratas, la reputación de una agencia estatal sobre la base de resultados genera credenciales para formar alianzas y autonomía para imponerse frente a rivales políticos. Lo mismo se puede decir de políticos: autoridades que gozan de trayectoria o que consiguen buenos resultados, cuentan con mayor agencia para plantear nuevos retos.

Sin embargo, los políticos no siempre aplican la ley. Precisamente, una nueva literatura ha discutido la discrecionalidad de la decisión. Dos son las razones que se atribuyen: o los costos de intervención resultan muy altos (Slater y Kim, 2014) o poco convenientes para fines electorales. Autoras como Holland (2017) en el estudio de políticas informales en América Latina, han mostrado como agencias con capacidad optan por aplicar o no la ley para ganar electores mientras que Garay (2016) presenta cómo la competencia entre partidos políticos nacionales y la movilización social fueron factores decisivos para explicar la adopción de políticas de protección social en la región.

Teniendo estos conceptos en mente, procedemos a explorar el caso de San Martín. Primero, presentamos evidencia que muestra los avances de la región en política territorial. Segundo, mostramos cómo se relacionan nuestras variables con en el caso de estudio. Finalmente, concluimos con algunos hallazgos del caso.

\section{El llamado «milagro» San Martín}

Las políticas de gestión territorial en San Martín nacieron de una necesidad: planificar y cuidar un territorio en declive. Y no era para menos. A inicios de la década de 1990, la región enfrentaba un escenario crítico. La deforestación, el narcotráfico y el terrorismo componían un panorama de violencia y desorden en la región.

La construcción de la Marginal de la Selva, una carretera que conectaría al país, le devolvió el protagonismo a la región. Hecha durante el gobierno de Belaunde, bajo un discurso que promovía la colonización de la selva para fomentar el desarrollo agropecuario, pronto mostró las consecuencias de una mala planificación. La migración interna se produjo de forma desordenada mientras que el suelo ácido, anunciado fértil, promovió el cultivo de hoja de coca y convirtió a la región en un bastión del narcotráfico (Paredes y Manrique, 2016; Manrique, 2015). A la par, la entrada de Sendero Luminoso y el MRTA en el Alto Huallaga, reforzó un escenario tétrico y fragmentado.

Sin embargo, durante estos años, la región también experimentó un dinamismo social. El intento de descentralización de 1989 movilizó a la población en defensa de la autonomía; el narcotráfico generó una coalición impulsada por la cooperación internacional a favor del desarrollo alternativo y los desastres ambientales, fomentaron el surgimiento de ONG interesadas en el desarrollo sostenible. Incluso en lo político, restringido por un escenario autoritario y centralista, San Martín pudo 
establecer una agenda propia haciendo uso de los espacios restringidos. En suma, como indican otros autores, pese a los legados de violencia, es posible advertir una recomposición del tejido social a mediados de la década de 1990 (Zárate, 2003) liderada por una élite regional interesada en proyectos de desarrollo y planificación estratégica (Meléndez, 2004, p. 30).

A la fecha, la región ha dado avances importantes. El «milagro» San Martín es distintivo, aunque nuevos estudios revelan los límites del modelo de desarrollo alternativo frente a los remanentes de cultivo de coca (Moscoso, 2018). Pese a ello, la descentralización aparece como una oportunidad, permitiendo el desarrollo de políticas territoriales y pioneras que representan al país a nivel internacional. En esta narrativa, los análisis suelen privilegiar la intervención de la cooperación internacional o de agencias nacionales. Sin embargo, existen otros factores que explican su continuidad. Para entender esto procederemos de la siguiente forma. Primero, documentamos los avances de la región en políticas territoriales y ambientales; segundo, mostramos la importancia de las relaciones entre el gobierno regional y la sociedad civil y finalmente, mostramos la importancia del liderazgo político.

\subsection{Las políticas de gestión territorial en San Martín}

A nivel mundial, las políticas ambientales han cobrado importancia ante la amenaza del cambio climático. Esto ha generado una agenda internacional en aras de la sostenibilidad del territorio. Aunque el Perú forma parte de muchos de esos acuerdos, la implementación de políticas ambientales muestra aún un desarrollo incipiente. Con relación a la década de 1990 existe un avance, que se revela en legislación vasta y alineada a las exigencias de la comunidad internacional, pero en donde persiste el deterioro ambiental (Gómez, 2019). Los tratados comerciales y organismos de cooperación han impulsado avances, siendo el más notorio la creación del Ministerio del Ambiente (Minam) en 2008, con políticas y directivas que no se cumplen a cabalidad. A la par, algunas agencias ambientales han visto un recorte de sus funciones ${ }^{3}$.

Si el escenario nacional aparece poco optimista, el subnacional es aún más complejo. Con la descentralización, los gobiernos regionales recibieron distintas funciones. Desde elaborar planes ambientales, pasando por otorgar concesiones forestales o impulsar el ordenamiento territorial, el espacio subnacional fue visto como un brazo del gobierno central. Sin embargo, a la fecha, los resultados son

\footnotetext{
3 Dargent y Urteaga (2016) grafican el impacto que tuvo la presión de actores económicos y de agencias estatales en el alcancey recorte delasfunciones dela OEFA (Organismo de Evaluación y Fiscalización Ambiental), lo que impidió superar esa resistencia inicial. Asimismo, funciones como el ordenamiento territorial han sido delegadas a nuevas agencias estatales, limitando el margen de intervención de la entidad.
} 
deficientes. En las regiones amazónicas, los recursos suelen ser exiguos, las estructuras administrativas no responden a la realidad del territorio y la capacidad es baja (Dourojeanni, 2013). Esta debilidad ha sido aprovechada por actores ilegales que no temen en desafiar la autoridad estatal a través de prácticas como la minería ilegal, la tala o la ocupación en zonas de cuenca.

Dentro de este escenario negativo, San Martín aparece como una excepción. En los últimos ańos, es posible observar un aumento en los recursos administrativos del gobierno regional, mejorando la intervención en el territorio. Como mostraremos, creemos que esto se explica principalmente desde las relaciones entre el Estado y la sociedad, las cuales han tenido un resultado positivo en otras políticas similares ${ }^{4}$. Para ello, nos centramos en cinco ejes: institucional, legal, económico, burocrático y en los resultados propios de la agencia.

En San Martín, la política territorial está definida desde un enfoque sistémico. El territorio es entendido desde la interrelación entre componentes biofísicos, sociales, económicos y políticos, elemento que está presente en el discurso del cuerpo burocrático. Para la comunidad sanmartinense, el ideal es que los instrumentos de ordenamiento territorial definan la intervención del Estado en estos otros ámbitos.

En lo institucional, la región ha dado avances importantes. En 2011, se creó la Autoridad Regional Ambiental (ARA), órgano rector de la política de recursos naturales, dentro de una reforma integral del aparato regional. Aunque depende del gobierno regional, cuenta con relativa autonomía técnica y funcional en sus tres direcciones. Esta agencia centralizó funciones antes dispersas a nivel territorial, forestal y ambiental y, permitió responder de forma más efectiva a la transferencia de funciones. El éxito de su creación, promovió la adopción del modelo por el resto de regiones amazónicas mediante un acuerdo internacional ${ }^{5}$.

Como órgano rector, la ARA establece lineamientos que guían la acción del resto de agencias. Los proyectos especiales, así como las gerencias y direcciones regionales definen sus acciones sobre la base de los instrumentos de la ARA. Por ejemplo, como muestra Kaulard (este número), este enfoque sistémico ha sido el punto de partida para la identificación de cadenas productivas — bajo la idea de comercio agregado y comercio justo- de la Gerencia de Desarrollo Económico. Dentro de un contexto de commodities, San Martín busca posicionarse en mercados diferenciados y sostenibles ${ }^{6}$. Esto también se refleja en la creación de nuevas agencias como la Oficina de Promoción de la Inversión Privada Sostenible (OPIPS), financiada

\footnotetext{
4 Ver Che Piu y García (2011) en relación con las mesas REDD y Kaulard (este número).

5 El acuerdo Grey Towers (2011) fue promovido por USAID y firmado por las regiones del Consejo Interregional Amazónico (CIAM) para contribuir a la gestión sostenible, estableciendo la creación de una ARA en cada región.

6 Entrevista a José Enrique Delgado Mesía, octubre de 2018.
} 
por la cooperación internacional, que promueve la inversión sostenible junto al sector privado ${ }^{7}$.

Asimismo, el marco legal se muestra vasto, facilitando la intervención en el territorio. Durante el período 2006-2018, se aprobaron más de 63 ordenanzas ambientales, muchas pioneras en su tipo, que involucraron la participación de la sociedad civil. Un ejemplo es la zonificación económica ecológica (ZEE), instrumento vinculante que diagnostica la potencialidad del suelo ${ }^{8}$.

Las primeras experiencias de ZEE se dieron a escala local durante la década de 1990, con el apoyo de ONG y cooperantes. Con el proceso descentralización, los actores sociales impulsaron la elaboración de una ZEE regional a través de la Comisión Ambiental Regional, comprometiendo al gobierno regional a cumplir con las funciones transferidas. Como resultado, se creó una comisión técnica que involucró a autoridades políticas, la academia, ONG y empresas privadas? ${ }^{9}$. Desde el Estado, burócratas del gobierno como Wilmer Pérez y Debora Landa, cumplieron un rol clave para afianzar las relaciones entre el gobierno regional y la sociedad civil. Como resultado, en 2006, San Martín se convirtió en el primer gobierno regional en aprobar la ZEE, con recursos otorgados a través del presupuesto participativo. Esta experiencia resulta clave si consideramos que solo trece regiones culminaron el proceso para 2015, según el Minam.

Actualmente, este instrumento es piedra angular de la gestión regional. La ZEE permitió pasar de una visión agraria a una que prioriza el desarrollo sostenible, revelando que el 64,8\% del suelo servía para fines de conservación y solo el 15\% de la actividad agropecuaria (Gobierno Regional de San Martín [Goresam], 2008). Su naturaleza técnica, ha reducido el espacio para la influencia política (Correa, 2013), facilitando su continuidad en el tiempo. Para la ARA, la ZEE es la base para la toma de decisiones que se aplican en el resto de niveles de gobierno ${ }^{10}$.

Sin embargo, este no es el único hito en materia ambiental. A la ZEE se han sumado otras políticas construidas en el tiempo como el Plan Forestal Regional (2008) o la Política Territorial (2012), primeras en su tipo. Todos estos instrumentos también han seguido un proceso participativo que ha involucrado a actores nacionales e internacionales y ha generado información para la toma de decisiones. Recientemente, el gobierno regional aprobó la zonificación forestal $(2018)^{11}$,

\footnotetext{
7 Entrevista a Roiter Egoavil, octubre 2018.

8 La ZEE fue declarada de interés nacional en el año 2001 y reglamentada en 2004.

9 OR 027-2005-GORESAM.

10 Entrevista a Cristina del Águila, febrero 2016.

11 La zonificación forestal se enmarca dentro de la Ley Forestal y de Fauna Silvestre. Su diseño fue impulsado por la Declaración Conjunta de Intención firmada por Perú, Noruega y Alemania, con el fin de reducir las emisiones de GEI y la deforestación. Recibió el apoyo del PNUD por la cooperación noruega.
} 
impulsado mediante un convenio internacional y actores nacionales, que incluyó a agencias estatales como el Servicio Forestal y de Fauna Silvestre (Serfor) y a actores de la sociedad civil. Como vemos, la región ha aprovechado el marco legal nacional para aprobar políticas, involucrando a distintos actores. En palabras de una técnica, «el gran éxito de San Martín es que nos atrevimos, es diferente estar pegado a la norma que ver en el vacío de la norma una oportunidad $»^{12}$.

Tercero, se observa un incremento de los recursos financieros (Gráfico 1). El presupuesto ha aumentado de forma progresiva en las agencias involucradas y la ejecución presupuestal es alta. Dentro de los recursos, donaciones y transferencias de actores nacionales e internacionales, ocupan un lugar importante. Para 2015, estos significaron el $40 \%$ de los recursos. Aunque han disminuido en el tiempo — probablemente por la salida de la cooperación — son un activo importante En específico, la ARA recibe gran parte de este presupuesto. De acuerdo con Ceplan, este sigue una tendencia creciente: S/ 4464 millones en 2016, S/ 5779 en 2017 y S/ 8606 en 2017.

Gráfico 1. Presupuesto destinado a la función ambiental y ejecución presupuestal, 2009-2018 (millones de soles)

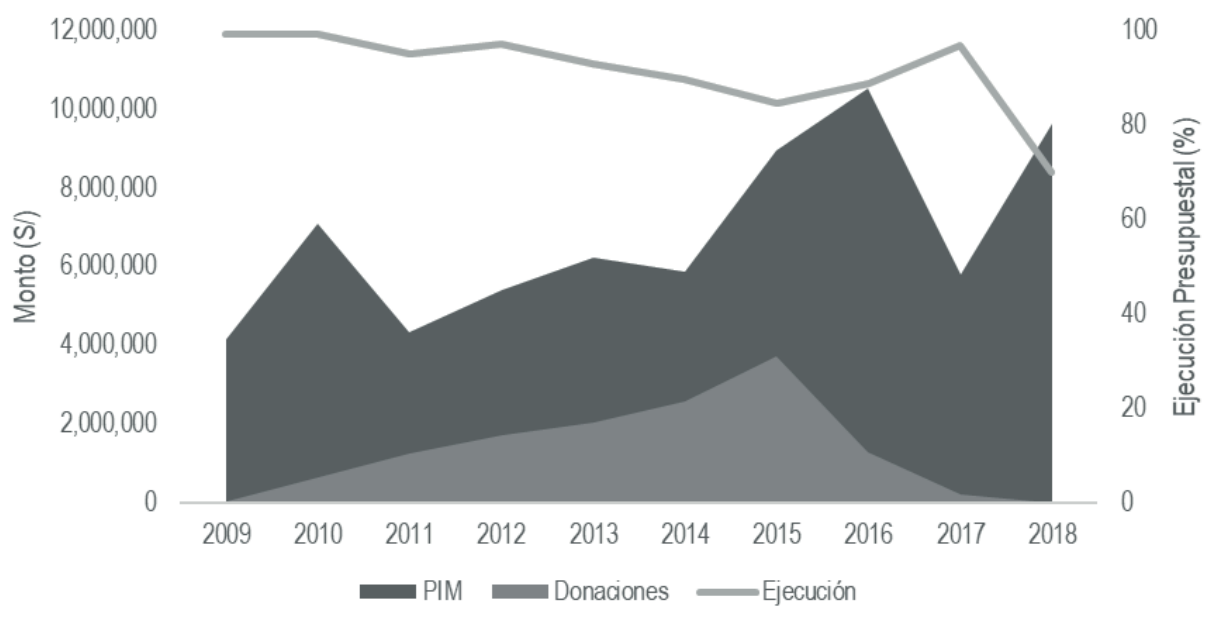

Fuente: Elaboración propia sobre la base de Portal Amigable del Ministerio de Economía y Finanzas. Incluye todo el presupuesto destinado a funciones ambientales en las distintas unidades ejecutoras.

Cuarto, en los últimos años, el personal en temas ambientales ha aumentado de forma considerable. En el caso de la ARA, se ha pasado de siete funcionarios a más de cien expertos. El personal reclutado se caracteriza por ser joven, con expertise en temas ambientales o territoriales y es, en su mayoría, sanmartinense. Los Gráficos

12 Entrevista a Karina Pinasco, enero 2016. 
2 y 3 reconstruyen el perfil de 33 funcionarios de alto rango de la ARA, quienes ocuparon gerencias y direcciones vinculadas al área de estudio durante el período 2006-2018

Como observamos, estos son egresados de carreras vinculadas a las ciencias naturales como ingeniería o biología y provienen de universidades similares. Esto resulta congruente con las entrevistas realizadas, donde se resalta que San Martín se caracteriza por una alta cantidad de técnicos ambientales que trabajan en la región ${ }^{14}$. Asimismo, provienen de espacios de estudio similares lo que genera una red de profesionales conocidos. Para los trabajadores, este espíritu de cuerpo se refleja en un discurso común que defiende la sostenibilidad del territorio como contraposición a la mala regulación de la década de $1980^{15}$. De este modo, el cuidado del medio ambiente es identificado como una tarea propia del sanmartinense (Correa, 2013). En la práctica, estos actores han permitido que no se caiga el proceso desde adentro, siendo un brazo para otros activistas locales ${ }^{16}$.

Gráfico 2. Profesión de directivos de alto rango vinculados al desarrollo territorial (\%)
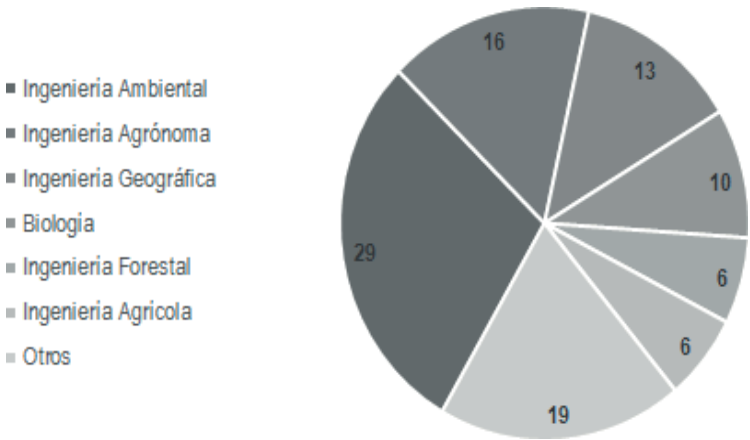

Fuente: Elaboración propia sobre la base de Gobierno Regional de San Martín y Superintendencia Nacional de Educación Superior Universitaria.

\footnotetext{
13 Para la elaboración de esta base, se rastrearon las resoluciones ejecutivas de designación de funcionarios, disponibles desde 2006. Las agencias seleccionadas comprenden a la Autoridad Regional Ambiental y a las áreas que permitieron su formación. En específico, la Gerencia de Recursos Naturales y Gestión del Medio Ambiente, la Subgerencia de Conservación de Recursos Naturales, la Gerencia General de Planeamiento, Presupuesto y Administración Territorial y la Subgerencia de Administración Territorial.

14 Entrevista a Sylvia Reátegui, diciembre 2015.

15 Entrevista a Carlos Miranda, junio 2016.

16 Entrevista a Karina Pinasco, enero 2016.
} 
Gráfico 3. Centro de estudios de funcionarios de alto rango vinculados al desarrollo territorial (\%)

- Universidad Nacional de
San Martin
- Universidad Nacional
Agraria de La Molina
- Universidad Nacional
Agraria de la Selva
- Ricardo Palma
- Universidad Nacional
Pedro Ruiz Gallo
- Otros

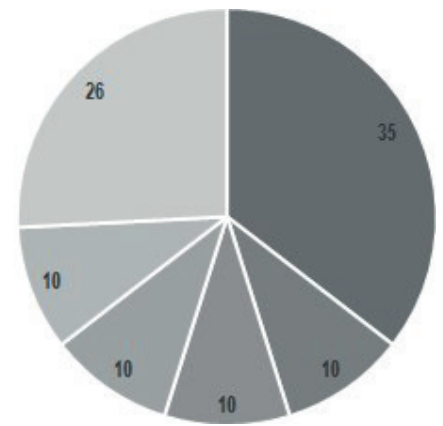

Fuente: Elaboración propia sobre la base de Gobierno Regional de San Martín y Superintendencia Nacional de Educación Superior Universitaria.

Sin embargo, se advierte una alta rotación en las instancias más altas, propia de una burocracia informal y débil como la peruana. Pese a ello, existe continuidad en las capas intermedias, incluso tras el cambio de gestión ${ }^{17}$. Quienes ingresan o salen de la ARA provienen de espacios similares: agencias ambientales regionales, nacionales, ONG locales o cooperación internacional, componen el mercado laboral. Esta alternancia permite construir redes que agilizan el trabajo a través de vínculos formales e informales y es también visible en otras áreas como la de desarrollo económico ${ }^{18}$.

El perfil de una exfuncionaria resulta ilustrativo. Karina Pinasco, bióloga sanmartinense, lideró el proceso de la ZEE desde el IIAP (centro de investigación), trabajó en GTZ (cooperación internacional) y luego asumió brevemente la Gerencia de Recursos Naturales del gobierno regional. Su gestión fue clave para iniciar la transferencia de funciones, apalancar recursos de la cooperación y sentar la agenda de política territorial. Tras su salida, Pinasco se dedicó a AMPA, su ONG, desde donde trabaja activamente con el gobierno regional. Actualmente, AMPA administra una de las concesiones de conservación, una modalidad de conservación que involucra a la sociedad civil en el cuidado del territorio y ha asumido el liderazgo de su junta de concesionarios. Asimismo, se encuentra conectada a múltiples redes a nivel internacional y es un soporte en el desarrollo de políticas territoriales, ambientales y económicas, ofreciendo asesoría legal y técnica.

Estas mejoras se trasladan a resultados. San Martín ha dejado de ser la región más deforestada del Perú para convertirse en un modelo. Aunque para 2016, la pérdida

\footnotetext{
17 Entrevista a Eduardo Huánuco, febrero 2016.

18 Molina y Arguedas (2015), documentan el proceso de modernización regional, resaltando la existencia de un cuerpo burocrático comprometido, profesional y sanmartinense mientras que en Kaulard (este número) hace lo propio en relación a las políticas de desarrollo económico, identificando una alta rotación entre la cooperación internacional, ONG locales y agencias estatales.
} 
de bosques ascendía al 8\% del territorio, es posible observar un retroceso sostenido a diferencia de otras regiones como Madre de Dios y Ucayali (Gráfico 4). En comparación de 2010, la tasa de deforestación muestra una reducción del 59\% en 2016 que aspira, idealmente, alcanzar una deforestación cero.

Esto se condice con los resultados en los esfuerzos de conservación. Sobre la base de la ZEE, se han implementado políticas para cuidar el territorio que involucran a la sociedad civil. Actualmente, cerca del $50 \%$ de la región se encuentra bajo alguna modalidad de conservación (Mapa 1). Estas iniciativas de manejo comunitario, compatibilizan la conservación con el asentamiento poblacional planificado y el desarrollo económico (D’Amico, 2015, p. 216). De acuerdo al sistema de información, en 2018, San Martín contaba con seis áreas naturales protegidas (22\% del territorio), cuarenta concesiones de conservación — cuatro de ellas con contratos agroforestales- y cerca de 7\% del suelo bajo modalidad de recuperación.

La construcción de estas políticas no ha estado exenta de tensiones con el gobierno central y de otros actores locales, como veremos más adelante. Inicialmente, el gobierno nacional se mostró reacio a aprobar cambios que implicaban una visión alterna de desarrollo. Este "dolor de cabeza», fue defendido por la ley. En palabras de una experta, «bajo la Ley Orgánica de Gobiernos Regionales tenemos la competencia de ordenar nuestro territorio y la libertad de aprobar políticas ${ }^{19}$. El éxito de las políticas ha convertido a San Martín en un laboratorio de experiencias desde donde el Minam ha sacado directivas ${ }^{20}$. Esto explicaría por qué, pese al esfuerzo de otras regiones amazónicas en replicar el modelo, los resultados han sido limitados. Sin embargo, en la actualidad, San Martín trabaja de la mano con instituciones como el Servicio Nacional de Áreas Naturales Protegidas (Sernanp), el Serfor, el Programa Nacional de Conservación de Bosques para la Mitigación del Cambio Climático (PNCBCC), entre otros.

Cabe agregar que este no es un modelo perfecto. Primero, los avances en el marco legal no siempre aterrizan en una implementación efectiva. En algunas zonas persiste el narcotráfico y la deforestación sea por la ausencia del Estado o porque las alianzas con la sociedad civil no resultan suficientes para garantizar la fiscalización continua del territorio. Segundo, las políticas no siempre contemplan la realidad de organizaciones sociales o pequeñas empresas, cuya adaptación a la ley supone costos. Esto cobra más importancia frente a la tolerancia a la gran empresa, parte de la cual promueve el cultivo de la palma aceitera ${ }^{21}$. Finalmente, aunque la capacidad ha aumentado, los casos de corrupción no están ausentes.

19 Entrevistaa Cristina del Águila, febrero 2016.

20 Entrevista a Eduardo Huánuco, febrero 2016.

21 Se calcula que la producción de palma ascendió a 27559 hectáreas para 2016. 
Gráfico 4. Deforestación en regiones amazónicas, 2001-2016 (hectáreas)

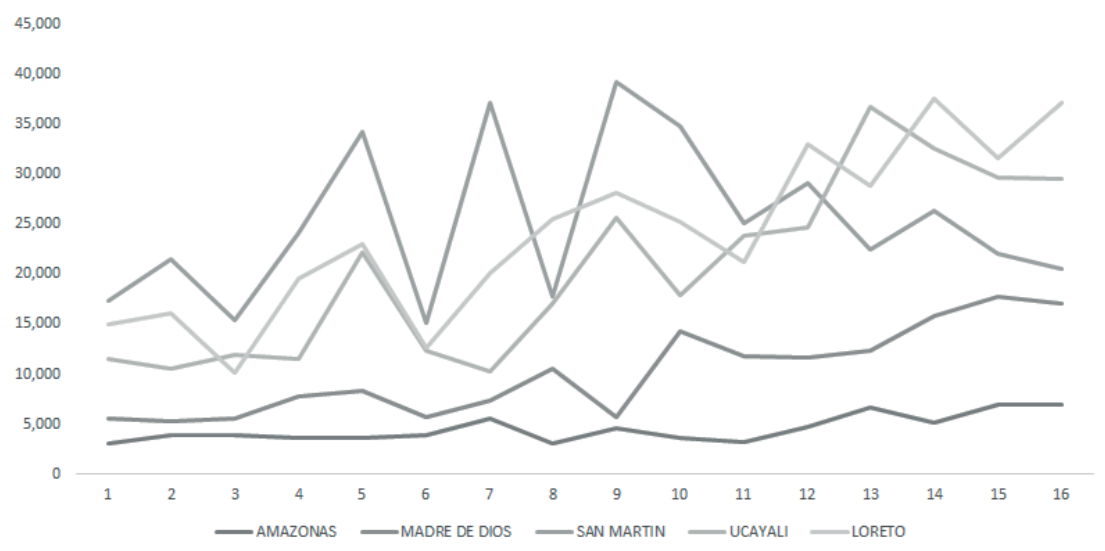

Fuente: Elaboración propia sobre la base del Programa Nacional de Conservación de Bosques.

\section{Mapa 1. Tipos de uso del suelo en San Martín}

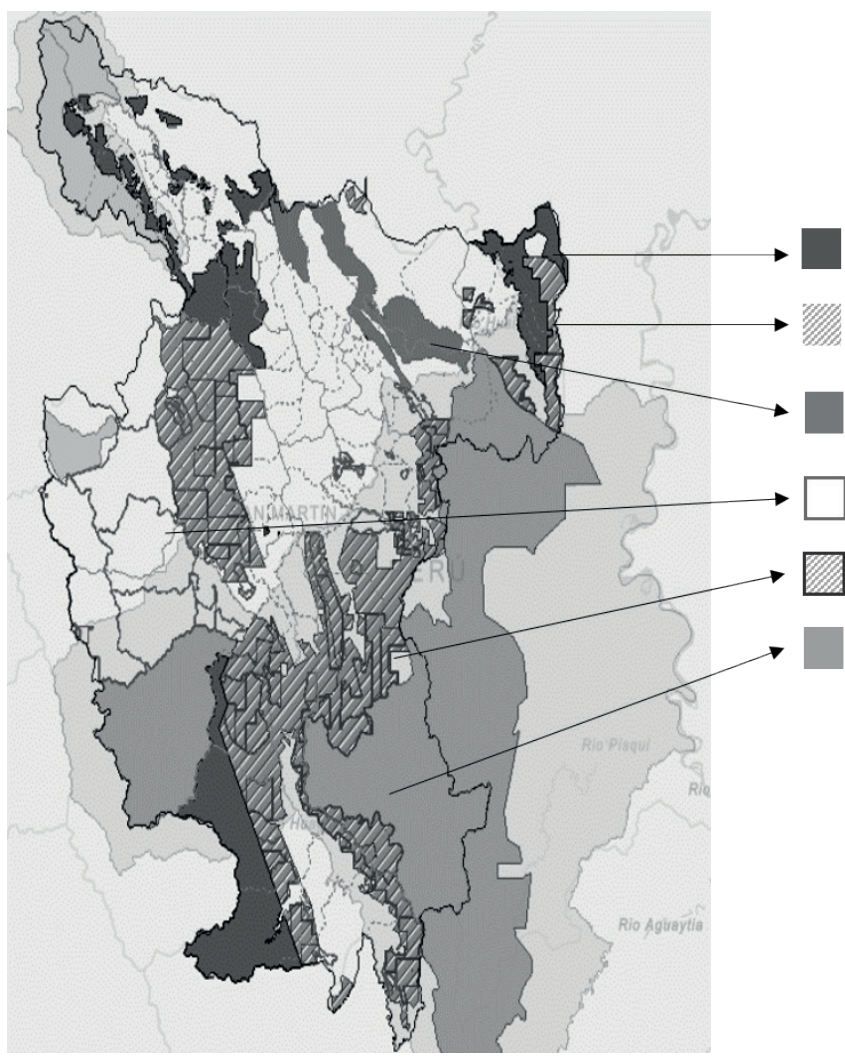

\section{LEYENDA}

Zonas de Recuperación y Conservación de Ecosistemas

Bosques de producción permanente

Áreas de Conservación Regional

Concesiones para conservación Concesiones con fines maderables

Parques Nacionales

Fuente: Sistema de Información Ambiental Regional (SIAR) San Martín. El mapa recoge solo algunas categorías escogidas por la autora. Información actualizada a 2017. 
Pese a ello, los entrevistados coinciden en señalar a San Martín como la región con más avances a materia ambiental. La presencia de una visión de desarrollo regional propia — en contraste a la apuesta nacional que prioriza la actividad extractiva — es un hito que continúa en el tiempo. Para el ex gobernador regional, el desarrollo no se encuentra en la minería sino en actividades sostenibles ${ }^{22}$. En la siguiente sección nos remitimos a este interés, el cual consideramos, proviene de la escena local. Como resume un entrevistado: «San Martín ha avanzado solo porque quería avanzar solo» ${ }^{23}$.

\subsection{Los actores sociales en San Martín}

\subsubsection{La crisis de la década de 1980}

El trabajo de campo realizado revela la importancia de las sinergias entre actores sociales y el Estado en el enforcement de las políticas ambientales. Al hablar de sociedad civil, haremos referencia a diversos grupos de colectivos que conviven pacíficamente y manifiestan relaciones de poder, ya sea de resistencia o de inclusión frente al Estado (Oxhorn, 1998). Si bien la sociedad civil peruana se caracteriza por ser débil y fragmentada (ver Panfichi, 2011), nuestro caso de estudio revela una organización funcional.

En efecto, los entrevistados destacan el rol de la sociedad civil como esencial en el impulso de políticas territoriales y ambientales. Para Debora Landa, funcionaria del gobierno regional desde la primera gestión, «la gestión territorial en San Martín inicia por un componente social más que por una decisión política» ${ }^{24}$. Entender la demanda institucional por políticas ambientales, implica remitirnos a la historia de la región.

Como vimos en la sección anterior, durante la década de 1960, San Martín cobró notoriedad por la construcción de la carretera Marginal de la Selva ${ }^{25}$, una vía pensada en convertir a la selva en un espacio de desarrollo energético y agropecuario que dotara de alimentos a la costa. Belaunde quería integrar al país y aumentar la frontera agrícola, incluso en lugares donde el suelo no era propicio, con un desprecio claro a la conservación del ecosistema (Dourojeanni, 2017). Sus iniciativas recibieron el respaldo financiero de Estados Unidos. Durante sus gobiernos, se crearon instituciones nacionales como la Oficina Nacional de Evaluaciones de Recursos Naturales (Onern) o el Instituto Nacional de Desarrollo (Inade), que realizaron estudios que aseguraban la productividad agraria. Sin embargo, los esfuerzos por guiar el potencial agrario se vieron limitados por una realidad desbordante.

\footnotetext{
22 Entrevista a Víctor Noriega, octubre 2018.

23 Entrevista a Rubén Paitán, junio 2016.

24 Entrevista a Débora Landa, febrero 2016.

25 La carretera Marginal de la Selva comenzó en el primer gobierno de Fernando Belaunde Terry y fue culminada en el segundo.
} 
Más pronto que tarde, los problemas aparecieron. La migración interna llevó a una ocupación desordenada del suelo, con miles de hectáreas deforestadas y quemadas para hacerse paso. La promesa de productividad agraria chocó con un suelo heterogéneo. Frente al monocultivo de arroz y maíz, la hoja de coca se convirtió en un producto más ventajoso. Paredes y Manrique (2016) grafican los problemas que afrontó el Alto Huallaga a través del estudio del corredor Tingo María - Tocache Campanilla, un piloto de colonización que recorrió San Martín y Huánuco. El Estado invirtió miles de millones para alentar la migración, desarrollar infraestructura y financiar pequeños productores. No obstante, durante las décadas de $1960 \mathrm{y}$ 1970, la demanda por tierras sobrepasó a la oferta, generando presión en el suelo. No solo eso, este resultó ser poco productivo y, ante la crisis agraria, sus productos poco rentables. Todo ello, abrió camino a la coca. En sus palabras, «los colonizadores en aprietos migraron a la coca para subsistir y cambiaron su confianza del apoyo de un Estado desvanecido a la dependencia en la producción de coca ilícita» (2016, p. 76).

Como consecuencia, San Martín se convirtió en el centro del narcotráfico. $\mathrm{Y}$ ante la represión inicial del Estado, los productores cocaleros encontraron en organizaciones subversivas como Sendero Luminoso a un aliado que les daba protección a cambio de ganancias para financiar sus propias actividades (Manrique, 2015, pp. 39-40). En suma, el escenario en la región era desolador: territorios ocupados, ecosistemas erosionados, coca por doquier y terror fueron sus principales saldos.

No obstante, a la par de la violencia e inseguridad, se gestaron cambios importantes. La visibilidad de la Amazonía - y en particular de San Martín— animaron el ingreso de nuevos actores en el territorio. Primero, con relación al narcotráfico. El Estado, de la mano de organismos internacionales, buscó erradicar el cultivo de coca. Aunque sus acciones serían fructíferas años después, gracias a los programas de desarrollo alternativo, sentaron un precedente. Segundo, los legados ambientales animaron el ingreso de cooperantes y el surgimiento de ONG locales como Centro de Desarrollo e Investigación de la Selva Alta (Cedisa) (1981), Centro de Estudios y Promoción Comunal del Oriente (Cepco) (1985) y Promoción y Desarrollo de la Mujer (Prodemu) (1984). Alineadas a una agenda mundial, interesada en conciliar la actividad económica con el desarrollo sostenible y la biodiversidad ${ }^{26}$, estas organizaciones dirigieron sus esfuerzos a pensar el desarrollo regional. Tercero, nuevas demandas territoriales fortalecieron la organización local. De esta época datan la Federación Agraria Selva Maestra Región San Martín y el Frente de Defensa de los Intereses de la provincia de San Martín (1986), el cual defendió la creación de una región autónoma frente a los intentos de regionalización, siendo clave para impedir la formación de la macrorregión La Libertad - San Martín en 1989.

26 Durante la década de 1970, se llevaron a cabo las primeras conferencias mundiales en materia de ambiente y sostenibilidad, organizadas por la ONU. 
Antes de explicar los vínculos entre la sociedad civil y el Estado, resulta preciso hacer tres precisiones sobre la cooperación internacional. Para comenzar, su intervención no fue homogénea. Las cooperantes de cada país priorizaron distintas actividades y metodologías: agendas de género, ambiente, educación o agricultura variaron entre una y otra. Segundo, no fue estática pues es posible ver una evolución de los intereses en el tiempo (Tabla 1). Finalmente, la efectividad de la cooperación parte del interés regional que, a su vez, impulsa nuevos proyectos. Aunque los cooperantes son un activo de ideas y recursos, sin el interés de actores locales, la continuidad de estos proyectos en el tiempo sería inviable. Estos, además, no imponen sus agendas. De acuerdo con los entrevistados, las iniciativas de la cooperación fueron adaptadas a la realidad sanmartinense, bajo enfoques que no siempre fueron compatibles. Para nuestro caso de estudio, sostenemos que tanto las organizaciones sociales como las autoridades políticas aprovecharon las oportunidades de la cooperación y delimitaron una agenda de desarrollo regional propia.

Tabla 1. Agendas promovidas por la cooperación internacional

\begin{tabular}{|c|c|c|c|}
\hline Década & Temas & País cooperante & Nombre del cooperante \\
\hline \multirow[t]{4}{*}{$1980-1990$} & \multirow{4}{*}{$\begin{array}{l}\text { Asistencia técnica, desarrollo } \\
\text { rural, género, gestión terri- } \\
\text { torial, salud comunitaria, } \\
\text { tecnificación agraria }\end{array}$} & Holanda & Cebemo, Memisa \\
\hline & & Canadá & $\begin{array}{l}\text { Fondo General de } \\
\text { Contravalor Perú-Canadá }\end{array}$ \\
\hline & & Bélgica & Broederlijk Delen \\
\hline & & Reino Unido & ITDG Soluciones Prácticas \\
\hline \multirow[t]{3}{*}{$1990-2000$} & \multirow{3}{*}{$\begin{array}{l}\text { Asistencia técnica en agroin- } \\
\text { dustria. desarrollo económico } \\
\text { alternativo, diversificación } \\
\text { económica, género, gestión de } \\
\text { desastres, gestión empresarial, } \\
\text { planificación estratégica }\end{array}$} & Estados Unidos & $\begin{array}{l}\text { USAID, Fondo de las } \\
\text { Américas }\end{array}$ \\
\hline & & Alemania & Misereor \\
\hline & & Reino Unido & ITDG Soluciones Prácticas \\
\hline \multirow[t]{5}{*}{$2000-2010$} & \multirow{5}{*}{$\begin{array}{l}\text { Comunidades nativas, } \\
\text { desarrollo alternativo, } \\
\text { gestión integrada de cuenca, } \\
\text { ordenamiento territorial, } \\
\text { programas de reforestación }\end{array}$} & Canadá & ACDI \\
\hline & & Holanda & SNV \\
\hline & & Estados Unidos & $\begin{array}{l}\text { USAID, Servicio Forestal de } \\
\text { Estados Unidos, CI } \\
\end{array}$ \\
\hline & & Suiza & WWF \\
\hline & & Alemania & Misereor, GIZ, KFW \\
\hline \multirow[t]{3}{*}{ 2010-Act } & \multirow{3}{*}{$\begin{array}{l}\text { Biocomercio, derechos } \\
\text { humanos, interculturalidad, } \\
\text { mecanismos de retribución } \\
\text { por servicios ecosistémicos, } \\
\text { poblaciones vulnerables }\end{array}$} & Estados Unidos & $\begin{array}{l}\text { USAID, CI, TNC, Andes } \\
\text { Amazon Fund, MacArthur } \\
\text { Foundation }\end{array}$ \\
\hline & & Alemania & GIZ, KFW \\
\hline & & Perú & SPDA \\
\hline
\end{tabular}

Fuente: Sobre la base de Augusto, 2017. 


\subsubsection{El despertar de la década de 1990}

La victoria de Alberto Fujimori y el autogolpe de 1992, eliminaron toda posibilidad de descentralización. El ideal de regiones fue reemplazado por los Consejos Transitorios de Administración Territorial (CTAR) ${ }^{27}$, manejados desde el centro. Pese a ello, San Martín hizo uso de los pocos espacios de coordinación para fomentar una agenda de desarrollo regional. Lejos de estancarse, los problemas de violencia, narcotráfico y destrucción de ecosistemas, fomentaron espacios de reflexión. A la fragmentación social, se sobrepusieron actores interesados en recuperar la infraestructura dañada y pensar a futuro. Como coinciden Zárate (2003) y Meléndez (2004), el tejido social se recompuso de la mano de una élite activa que reunió a un sector público y privado. Los actores locales provinieron de frentes distintos como la Cámara de Comercio, los alcaldes locales, la iglesia, ONG o nuevas apuestas políticas como el Movimiento Ideas. De esta forma, se construyó una masa crítica de profesionales y líderes orientados a la planificación (Pinedo, 2009, p. 33).

Dentro de estas iniciativas, lo ambiental emergió como un pilar clave. La deforestación, los deslizamientos y la expansión del monocultivo mostraron la importancia de entender el territorio. Dentro de una economía aún liderada por el narcotráfico, los actores locales se interesaron en delimitar un desarrollo productivo propio, independiente de las directivas nacionales y con un componente ambiental claro (Tenorio, Rodríguez y Neira, 2002). Como añade Pinedo, «irrumpe así la necesidad de introducir en los planes de desarrollo local y proyectos económico/productivos, el enfoque de prevención y mitigación de desastres como factor de sostenibilidad» (2009, p. 57). Algunos ejemplos grafican lo dicho. En San Martín, se llevó a cabo el primer Foro de Desarrollo Sostenible, se gestó la primera red de organizaciones locales y se realizaron experiencias inéditas en planeamiento estratégico que involucraron la participación de actores sociales. Estas iniciativas iniciaron en 1996 a nivel local, aprovechando la continuidad de las alcaldías municipales. Así, el Proyecto de Desarrollo de Gobiernos Locales permitió elaborar planes concertados en cinco provincias con el apoyo de ITDG, USAID y la Red San Martín de ONG. Sobre la base de esto, en 1998 se aprobó el primer Plan Estratégico Regional a nivel nacional. Dentro de un escenario autoritario y centralista, los actores locales trabajaron junto a la presidencia del CTAR para delimitar una visión de desarrollo que incluyó dentro de sus siete puntos a la conservación de recursos naturales. Para un exfuncionario del CTAR y exgerente de la ARA, los profesionales tenían una visión ambiental porque ya avizoraban los problemas que la mala planificación tenía en sus ecosistemas ${ }^{28}$.

\footnotetext{
27 Los CTAR restringían la autonomía regional en tanto no existían competencias transferidas a nivel subnacional y a que sus presidentes eran nombrados desde el centro.

28 Entrevista a Mario Ríos, junio de 2016.
} 
Desde la década de 1990, es posible advertir el surgimiento de nuevas ONG locales como TakiWasi (1992), Instituto para el Desarrollo y la Paz Amazónica (IDPA) (1996), Urku (2000), CIMA (Centro de Conservación, Investigación y Manejo de Áreas Naturales) (2002), Amazónicos por la Amazonía (AMPA) (2006) que, junto a iniciativas nacionales, aprovecharon los nuevos espacios de diálogo inaugurados por la transición democrática y la descentralización. Al respecto, es posible identificar a dos generaciones de actores. La primera, data de la década de 1980. Formada por profesionales que retornaron a San Martín por sus vínculos a empresas (Zárate, 2003, p. 35), estos actores simpatizaron con ideas de izquierda y cumplieron un rol clave en la lucha por la autonomía de la región. La segunda, es liderada por profesionales vinculados a ciencias ambientales, algunos de los cuáles abandonaron la región por los episodios de violencia. Actualmente, estos trabajan en ONG locales, agencias estatales y en la cooperación internacional, siendo un brazo importante del gobierno regional.

Desde la descentralización, se han gestado distintos instrumentos que recogen el desarrollo de San Martín. Por ejemplo, la instalación de la Mesa de Lucha Contra la Pobreza o la elaboración de Planes de Desarrollo Concertado, en distintas gestiones regionales, revelan la maduración de una visión (Tabla 2). Como veremos más adelante, aunque la relación entre sociedad y gobierno ha sido una constante, es en la gestión de César Villanueva donde se tornan más fluidas. En específico, además de la cooperación internacional, las ONG locales sirvieron de apoyo técnico al gobierno regional (Muñoz, Monsalve, Guibert, Guadalupe y Torres, 2016, p. 68).

Tabla 2. Visión regional en los Planes de Desarrollo Concertado, 2002-2018

\begin{tabular}{|l|l|l|}
\hline Planes concertados & Organización política & Visión regional \\
\hline $2004-2008$ & APRA & $\begin{array}{l}\text { «Región líder en ordenamiento participativo y uso } \\
\text { sostenible del territorio» }\end{array}$ \\
\hline $2008-2015$ & Nueva Amazonía & $\begin{array}{l}\text { San Martín, región verde } \\
\text { «Con desarrollo económico sustentado en un territorio } \\
\text { ordenado y en el manejo autónomo ysostenible de sus } \\
\text { recursos naturales» }\end{array}$ \\
\hline $2015-2021$ & Fuerza Popular & $\begin{array}{l}\text { Producción, inclusión y protección } \\
\text { «Modelo de región en bienestar social, competitividad } \\
\text { yaloración de nuestros recursos naturales y diversidad } \\
\text { biológica» }\end{array}$ \\
\hline
\end{tabular}

Fuente: Elaboración propia sobre la base de los Planes de Desarrollo Concertado.

\subsubsection{La continuidad ambiental}

Desde la primera gestión regional, San Martín ha virado hacia un enfoque que promueve la conservación y el desarrollo sostenible. Para ello, ha aprobado instrumentos 
técnicos que buscan una mejor planificación del territorio. Dentro de esta narrativa, los actores sociales han aportado en la política territorial a través de distintos repertorios.

Primero, como miembros de espacios participativos. En estos espacios, predominan profesionales con alto expertise técnico. Un primer espacio fue la Comisión Ambiental Regional, creada en 2001. Este fue clave para la elaboración de la ZEE, en tanto persuadió al gobierno regional a asumir las funciones delegadas y a asignar recursos $^{29}$, a través de herramientas como el presupuesto participativo. La CAR también ayudó en el diseño de políticas como la Estrategia de Biodiversidad Biológica o el Sistema Regional de Gestión Ambiental. Este espacio se mantuvo activo hasta 2011 y de acuerdo con los entrevistados, otorgó legitimidad al proceso aunque, en algunos casos, asumió más funciones de las que debía ${ }^{30}$.

Además, el gobierno regional cuenta con otros mecanismos como las mesas técnicas lideradas por la ARA en donde participan productores, ONG locales, cooperantes, comunidades nativas, entre otros. Estos abordan materias más específicas y entre las actividades se encuentran la reunión con actores claves, el diseño de políticas y la elaboración de diagnósticos. Sin embargo, dado el nivel de expertise, pueden convertirse en espacios restringidos.

Segundo, la sociedad civil contribuye con el enforcement a través de las modalidades de conservación del gobierno regional. Un ejemplo es la Red de Concesionarios que agrupa a las organizaciones sociales que cuentan con concesiones de conservación. Su tarea es cuidar el bosque y evitar la deforestación, desarrollando nuevas actividades económicas sostenibles. Actualmente, estas alcanzan a cuarenta organizaciones, formadas por asociaciones turísticas, comunidades nativas o productores. Aunque afrontan limitaciones logísticas, sin su apoyo, el gobierno regional no podría llegar a algunos espacios del territorio. Esto también se replica en otros espacios como el trabajo con poblaciones que viven en zonas de amortiguamiento de áreas de conservación o con los guardabosques voluntarios que custodian el bosque.

Esto no solo se limita al ámbito formal. Al provenir de espacios similares, los técnicos ambientales aportan con conocimiento y con una red de contactos que les es funcional para alcanzar los objetivos. De un lado, el expertise les permite plantear políticas sólidas. Estos actores cuentan con legitimidad frente a las autoridades, lo que les da marco de acción para proponer o mejorar las políticas. De otro, los contactos son útiles para canalizar financiamiento o agilizar trámites que, de lo contrario, se estancarían en un largo proceso burocrático. Solo así se explica, por ejemplo, la rápida aprobación de la zonificación forestal.

\footnotetext{
29 Entrevista a Karina Pinasco, enero 2016.

30 Entrevista a Eduardo Huánuco, febrero 2016.
} 
De igual forma, al interior del Estado, burócratas activistas canalizan los aportes de las ONG locales y con la Cooperación Internacional, quienes pueden tener una participación activa. Estos actores brindan conocimiento para el diseño de documentos y políticas. Por ejemplo, la técnica de una ONG señaló ser la autora de muchas de las ordenanzas regionales aprobadas por el Consejo Regional en materia ambiental ${ }^{31}$. Además, pueden brindar recursos logísticos o financieros. Algunas ONG han donado equipos para mejorar el cumplimiento de actividades de la ARA y la Cooperación Internacional ha financiado la contratación de personal en labores específicas. Finalmente, su importancia radica en que aseguran la continuidad de las políticas, pronunciándose públicamente o incentivando a que la gestión regional asuma compromisos.

Esta proximidad ha permitido que funcionarios con experiencia en el gobierno regional asuman cargos en ONG, la cooperación internacional o agencias estatales nacionales y viceversa. Pese a ello, esto también tiene limitaciones. La sociedad civil es una aliada pero dada su cercanía puede exceder en sus prerrogativas. En algunos casos, tienden a ser críticos cuando no son convocados no están de acuerdo y en la medida en que los espacios de concertación son voluntarios, la participación no siempre es activa. Además, dada su condición de intermediarios, puede dificultar la relación entre la ARA y las ciertas poblaciones (Egerlid, 2015) en su trabajo. Luego, para quienes carecen de contactos en la red, el acceso al Estado es más complicado. Para el director de una ONG, existe poco profesionalismo por parte del gobierno regional pues todo se logra por el lado amical lo que resulta en discrecionalidad en la entrega de derechos de conservación ${ }^{32}$. Finalmente, existen actores que no comparten el discurso.

Este último punto amerita mayor estudio. Al priorizar la conservación, la gestión regional impone una visión que puede no ser congruente con prácticas e intereses de otros actores. En ese sentido, algunas ONG como Wawa Wasi, Paz y Esperanza o CAAAP son críticos con la labor del gobierno regional. Desde su punto de vista, modalidades de conservación como las áreas naturales protegidas, zonas intangibles o concesiones para la conservación pueden sobreponerse al interés de la población. Dos ejemplos resultan ilustrativos. Por una parte, la titulación. Como muestra Egerlid (2015), el gobierno prioriza las concesiones para conservación — que otorgan permiso bajo ciertas condiciones - antes que la titulación indígena. Desde la década de 1990 no se observan avances en esta materia, razón por la cual muchas comunidades optan por las concesiones. En la actualidad, esto ha generado conflictos dentro de comunidades que, asesoradas por distintas ONG, priorizan una u otra estrategia o en espacios ya conservados, en donde comunidades nativas reclaman la consulta previa.

31 Entrevista a Cristina del Águila, febrero 2016.

32 Entrevista a Daniel Vecco, junio 2016. 
Situación similar afecta a los productores. El desarrollo económico — pensado en los instrumentos territoriales - ha impuesto nuevas reglas de juego. Hoy en día, el gobierno regional prioriza cadenas productivas y aunque el arroz o el maíz siguen siendo importantes, se buscan productos diferenciados como el sacha inchi, el cacao, el café o el limón tahiti. No obstante, esto no asegura resultados rentables. Esto es un reto en tanto el gobierno regional debe garantizar que el viraje económico no sea en vano mientras que los productores deben invertir para adecuarse al nuevo marco. De todo lo dicho, queda claro que, en San Martín, los actores sociales han cumplido un rol clave en la institucionalización de las políticas territoriales y ambientes. Con una visión clara, se asemejan a una comunidad epistémica que desde dentro y fuera del Estado, buscan cuidar el territorio. Esta demanda local ha hecho posible que la política sobreviva en el tiempo ante el cambio de los actores políticos.

\subsection{Liderazgo político}

La voluntad política es otra variable clave para explicar la acción o inacción estatal. En el caso de San Martín, la gestión de César Villanueva (2006-2014) posicionó a las políticas territoriales en el centro del debate regional. Como fundador de Cedisa, Villanueva estaba familiarizado con esta agenda y conocía a sus promotores. Precisamente, la creación del movimiento regional Nueva Amazonía en 2001, respondió a una inquietud por llevar la agenda de desarrollo al Gobierno Regional. Como señala Meléndez, «era básicamente una organización política formada por profesionales locales con experiencia en el sector no-gubernamental» (2004, p. 30). La importancia de su liderazgo se puede ver en dos frentes: la campańa electoral y la legitimidad de su figura.

En 2002, Nueva Amazonía participó en las elecciones por primera vez. Ya entonces, su Plan de Gobierno incluía temas novedosos como el ordenamiento del territorio y la vocación productiva de la región, que venían siendo impulsados por otros actores sociales. Este discurso, fue retomado con fuerza en 2006, insistiendo en el desarrollo sostenible. Como muestra el Gráfico 5, en esa oportunidad, Nueva Amazonía arrasó en las elecciones, superando al segundo lugar por más de veinte puntos porcentuales. Para algunos, Nueva Amazonía gana porque ya había conciencia ambiental en San Martín ${ }^{33}$.

\footnotetext{
33 Entrevista a Lenin Quevedo, febrero y junio 2016.
} 
Gráfico 5. Intención de voto en las elecciones regionales de San Martín (\%), 2002-2014

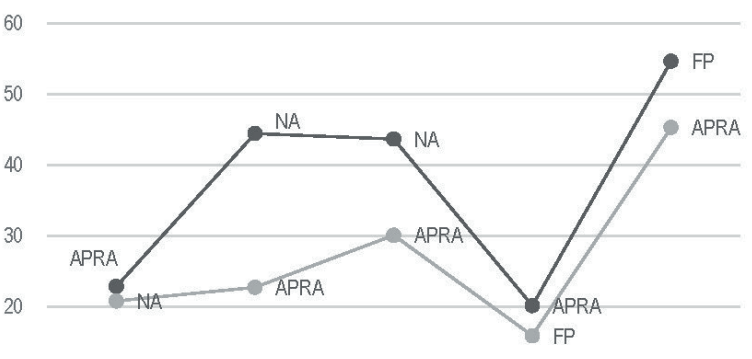

\begin{tabular}{|l|c|c|c|c|c|}
\cline { 2 - 6 } \multicolumn{1}{c|}{} & 2002 & 2006 & 2010 & $2014-1$ & $2014-2$ \\
\hline - & 22.84 & 44.48 & 43.7 & 20.13 & 54.69 \\
\hline$\multimap-$ Primer puesto & 20.78 & 22.72 & 30.09 & 15.87 & 45.32 \\
\hline
\end{tabular}

Fuente: Elaboración propia a partir de Infogob.

En las elecciones de 2006, Villanueva resaltó la importancia de armonizar el desarrollo económico y ambiental, con propuestas específicas vinculadas a la ZEE y la diversidad biológica. Si bien esto estaba presente en el discurso de otros candidatos, su afinidad con las ONG lo convertía en el candidato más idóneo en el tema. Ya en la gestión, posicionó el eslogan «San Martín, región verde», declarando de interés regional la recuperación de los recursos naturales y urgiendo a la elaboración de planes para políticas ambientales. Al posicionar el eje ambiental como clave en su gestión, politizó el tema. En la primera gestión se consiguieron resultados clave: la transferencia de funciones, la aprobación del Plan Forestal Regional que ya planteaba la creación de una agencia ambiental y el incremento de fondos en materia ambiental.

Sin embargo, para muchos esto no fue suficiente. En la campaña de reelección, sus críticos aludieron a la idea de «región marrón», precisamente para deslegitimar su candidatura. Como señalan los entrevistados, la presión por dar resultados, hizo que Villanueva enfatizara aún más las políticas ambientales. En ese sentido, también posicionó el tema ambiental a nivel interno. Como vimos, aunque la ZEE es un instrumento vinculante, su aplicación está sujeta a la voluntad política. Y en ese sentido, ubicó a las políticas territoriales como un filtro previo para el diseño de planes y la inversión regional. Tras la creación de la ARA y ante la resistencia de otras gerencias regionales, Villanueva sentenció: «De ahora en adelante, nadie va a tener un centavo en temas de inversión y de actividades si no tienen el visto bueno de la ARA $^{34}$ ", estableciendo prioridades y forzando a la nueva institución a responder a la demanda de inversión.

34 Entrevista a Sylvia Reátegui, diciembre 2015. 
Resulta importante aclarar que, aunque Villanueva manejaba el tema ambiental, carecía de un conocimiento especializado. Es justamente en la convocatoria y confianza de un brazo técnico, en donde encuentra el expertise para implementar las políticas de largo aliento. Como señala Karina Pinasco, primera gerente de Recursos Naturales, «Si bien César no inició el proceso, simplemente dijo "quiero que se haga”. Me dio carta para hacerlo, cosas que así nomás no encuentras ¿no?».

En la actualidad, el tema ambiental está presente en todas las campañas electorales. En 2014, todos los candidatos incorporaron el tema ambiental y seis de ocho hicieron referencia explícita a las políticas territoriales. Actores de la sociedad civil y medios locales suelen confrontar a los candidatos para garantizar la continuidad de las políticas ambientales. En la primera vuelta de 2014, los candidatos suscribieron un pacto ambiental que aseguraba la continuidad de las políticas de la gestión anterior. Esto disipó las dudas frente al nuevo gobernador regional, de quien se temía traería minería a la región. El mismo gobernador se refirió al incidente como un error pues «nadie en su sano juicio podría aceptar eso» ${ }^{35}$. En la práctica, Víctor Noriega supuso la continuidad de la política ambiental, a tal punto de ser criticado por gobernar con la agenda de Nueva Amazonía.

Un segundo elemento es la legitimidad del gobernador regional. Villanueva tenía una larga trayectoria como dirigente social, empresario e impulsor de una ONG local. Su relación con técnicos, cooperantes internacionales y organizaciones sociales, le daba credenciales políticas. Esto fue clave al asumir el gobierno y ayudó a la gestión. Respecto a la cooperación se afirma que dados sus logros, «la Cooperación lo veía y un poco más y le besaba los pies» ${ }^{36}$ mientras que a nivel político su prestigio «hizo que el gobierno central tuviera mucho más disposición con él que con otros presidentes regionales ${ }^{37}$ ».

Esto se grafica en tres acciones. Primero, San Martín fue la única región que pudo emprender un proceso de modernización regional, el cual precisamente permitió la creación de la ARA bajo una mirada sistémica. Segundo, gracias a los contactos dentro del Ministerio de Agricultura, fue la primera región en recibir las transferencias forestales, lo que permitió llevar a cabo los planes y políticas ya diseñadas. Finalmente, fue la primera región donde la cooperación internacional asignó fondos de forma directa, lo que reafirma la confianza en los resultados de gestión. Esto no quita que el gobierno regional haya afrontado problemas, casos de corrupción han sido denunciados en más de una oportunidad. Sin embargo, esta certidumbre en el compromiso del gobierno con el desarrollo, abrió muchos frentes que fueron aprovechados por los impulsores del proceso.

\footnotetext{
35 Entrevista a Víctor Noriega, octubre 2018.

36 Entrevista a Sylvia Reátegui, diciembre 2015.

37 Entrevista a Raúl Molina, enero 2016.
} 
Frente a Villanueva, el liderazgo de Víctor Noriega aparece mucho más débil. El gobernador se divorció de la cúpula local de su propio partido político. Pese a las críticas, admite que ha continuado con lineamientos porque uno no puede descabezar una gestión cuando existen personas con expertise $e^{38}$. La vocación del gobernador regional por la continuidad se explica, precisamente, porque existe un legado de largo aliento que es sostenido por la burocracia regional y por algunos actores sociales. Además, los resultados en San Martín, han llevado a firmar nuevos convenios nacionales e internacionales que comprometen al proceso en el largo plazo. Actualmente, el gobierno regional es una vitrina externa que suele ser convocada para la implementación de pilotos o para la asistencia a eventos nacionales e internacionales.

\section{ConClusiones}

A lo largo del trabajo, se ha mostrado que San Martín ha construido una política territorial que sustenta la visión de desarrollo de la región. Dentro de nuestro análisis, hemos resaltado la importancia que tienen variables sociales y políticas para explicar su continuidad en el tiempo. En base a ello, es posible sugerir algunos hallazgos.

Primero, queda claro que los actores locales son claves en la promoción y continuidad de políticas. Es cierto que la cooperación internacional tiene un rol clave en la promoción de agendas y recursos, pero si se carece de un interés local, es poco probable que continúe en el tiempo. Esto explicaría por qué el resto de regiones amazónicas han sido menos exitosas al replicar la ARA. Contar con estas coaliciones puede ser especialmente útil en áreas poco atractivas o espacios débiles, aunque resulta también importante preguntarse por los actores que son excluidos de este discurso.

Segundo, el liderazgo político abre una ventana de oportunidad para impulsar agendas. Lalegitimidad del gobernador regional y su interésen el medio ambiente, permitió posicionar el tema ambiental tanto frente al gobierno central como dentro de la misma gestión. Por un lado, esto se tradujo en una mayor autonomía ya sea para crear la ARA, aprobar ordenanzas ambientales o adelantar la transferencia de funciones. Por otro, permitió alinear la visión de desarrollo con otras direcciones. Sin esta legitimidad, es claro que la agenda regional habría avanzado mucho más lento.

Finalmente, en un debate en donde la descentralización suele ser vista como un fracaso, el estudio invita a realizar mayores trabajos a nivel subnacional. Los avances en áreas de política específicas, aún si parecen poco atractivas, pueden generar información relevante para entender las variables que impulsan o restringen la capacidad estatal.

38 Entrevista a Víctor Noriega, octubre 2018. 


\section{ANEXos}

\section{Anexo 1. Hitos de la política territorial en San Martín}

\begin{tabular}{|c|c|c|}
\hline Año & Gestión & Hitos \\
\hline 2005 & APRA & Se aprueba la Política Ambiental Regional. \\
\hline 2006 & \multirow{14}{*}{$\begin{array}{l}\text { Nueva } \\
\text { Amazonía }\end{array}$} & Se aprueba la Zonificación, Económica, Ecológica. \\
\hline 2007 & & Se declara en proceso de modernización la gestión del Gobierno Regional de San Martín. \\
\hline 2008 & & Se aprueba el Plan Forestal Regional. \\
\hline 2009 & & $\begin{array}{l}\text { Se declara la necesidad e interés regional la implementación del Ordenamiento Territorial } \\
\text { de la región San Martín. }\end{array}$ \\
\hline 2011 & & Se aprueba el Reglamento de Organización y Funciones de la Autoridad Regional Ambiental. \\
\hline 2012 & & Se aprueba la Política Territorial de San Martín. \\
\hline 2013 & & $\begin{array}{l}\text { Se declara de interés público regional la conservación y protección de las cuencas } \\
\text { hidrógráficas de la región San Martín. }\end{array}$ \\
\hline \multirow[t]{7}{*}{2014} & & $\begin{array}{l}\text { Se aprueba la Estrategia Regional de Control y Vigilancia Forestal y de Fauna Silvestre } \\
\text { de la ARA. }\end{array}$ \\
\hline & & $\begin{array}{l}\text { Se declara como prioridad regional la elaboración y aplicación de la Zonificación y el } \\
\text { Ordenamiento Forestal en el departamento de San Martín. }\end{array}$ \\
\hline & & Se aprueba la actualización del Plan de Acción Ambiental Regional 2013-2021. \\
\hline & & $\begin{array}{l}\text { Se declara de interés regional las medidas relacionadas con la reducción de emisiones } \\
\text { provenientes de la deforestación y degradación de los bosquesylassalvaguardasambientales } \\
\text { y sociales que estas conllevan. }\end{array}$ \\
\hline & & Se aprueban políticas sostenibles para la región San Martín. \\
\hline & & Se definen lineamientos e iniciativas de gestión para implementar la PTR. \\
\hline & & Implementación del IDE-SM. \\
\hline 2015 & \multirow{10}{*}{$\begin{array}{l}\text { Fuerza } \\
\text { Popular }\end{array}$} & Se aprueba el Plan de Desarrollo Regional Concertado (PDRC) San Martín a 2021. \\
\hline 2016 & & Se aprueba la priorización de diez cadenas productivas en la región San Martín. \\
\hline \multirow[t]{2}{*}{2017} & & $\begin{array}{l}\text { Se aprueba el Plan de Implementación de la Zonificación Forestal (PIZF) del departamento } \\
\text { de San Martín. }\end{array}$ \\
\hline & & Inicia la actualización de la Política Ambiental Regional. \\
\hline \multirow[t]{6}{*}{2018} & & Se aprueba la Política Regional Ambiental. \\
\hline & & $\begin{array}{l}\text { Se aprueba el Plan Maestro 2018-2023 del Área de Conservación Regional Cordillera } \\
\text { Escalera. }\end{array}$ \\
\hline & & $\begin{array}{l}\text { Se declara como prioridad regional el Ordenamiento Agroterritorial en el departamento } \\
\text { de San Martín }\end{array}$ \\
\hline & & $\begin{array}{l}\text { Se aprueba el Reglamento de Supervisión, Fiscalización y Sanción Ambiental del Gobierno } \\
\text { Regional de San Martín. }\end{array}$ \\
\hline & & Se aprueba la Zonificación Forestal de San Martín. \\
\hline & & $\begin{array}{l}\text { Se aprueba el establecimiento del área de conservación regional de los Bosques de Shunté } \\
\text { y Mishollo - Boshumi. }\end{array}$ \\
\hline
\end{tabular}




\section{REFERENCIAS BIBLIOGRÁFICAS}

Abers, R. N. (2019). Bureaucratic Activism: Pursuing Environmentalism Inside the Brazilian State. Latin American Politics and Society, 61(2), 21-44. https://doi.org/10.1017/ lap. 2018.75

Abers, R. N. y Keck, M. (2009). Mobilizing the State: The Erratic Partner in Brazil's Participatory Water Policy. Politics \& Society, 37(2), 289-314. https://doi. org/10.1177/0032329209334003

Amengual, M. (2016). Politicized enforcement in Argentina. Nueva York: Cambridge University Press. https://doi.org/10.1017/CBO9781316476901

Augusto, M. C. (2017). Los orígenes sociales de la institucionalidad politica: una mirada a la gestión ambiental en San Martín (1998-2015) (tesis de licenciatura). Pontificia Universidad Católica del Perú, Lima.

Augusto, M. C., Dargent, E. y Rousseau, S. (2017). Más allá de la capacidad estatal: sociedad civil e implementación de políticas a nivel subnacional en Cusco y San Martín (Perú). Colombia Internacional, 90, 99-125. https://doi.org/10.7440/ colombiaint90.2017.04

Bersh, K., Praça, S. y Taylor, M. (2017). Bureaucratic Capacity and Political Autonomy: Within National States: Mapping the Archipelago of Excellence in Brazil. En M. Centeno, A. Kohli, D. Yashar y D. Mistree (eds.), States in Developing World (pp. 157-183). Cambridge: Cambridge University Press. https://doi.org/10.1017/ CBO9781316665657.007

Carpenter, D. (2001). The Forging of Bureaucratic Autonomy: Reputations, Networks and Policy Innovation in Executive Agencies 1862-1928. Princeton, NJ: Princeton University Press.

Centeno, M., Kohli, A., Yashar, D. y Mistree, D. (2017). States in Developing World. Cambridge: Cambridge University Press. https://doi.org/10.1017/CBO9781316665657

Correa, F. (2013). Gobernando el medio ambiente: el rol de los técnicos de una oficina regional de San Martín en la creación de políticas ambientales y territoriales (tesis de licenciatura). Pontificia Universidad Católica del Perú, Lima.

Che Piu, H. y García, T. (2011). Estudio REDD Perú: La situación REDD en el Perú. Lima: DAR y GIZ.

D’Amico, M. P.(2015). Debates sobre conservación y áreas naturales protegidas: paradigmas consolidados y nuevos horizontes. Letras Verdes. Revista Latinoamericana de Estudios Socioambientales 18, 208-226. https://doi.org/10.17141/letrasverdes.18.2015.1662

Dargent, E. (2008). Islas de eficiencia y reforma del Estado: Ministerios de Economía y Salud (1990-2008). Lima: CIES; SASE.

Dargent, E. (2014). Determinantes internacionales de la capacidad de las agencias estatales: lecciones a partir de Colombia y Perú. Apuntes, 41(74), 9-40. https://doi. org/10.21678/apuntes.74.701

Dargent, E. y Urteaga, M. (2016). Capacidad estatal y fuerzas sociales: explorando una relación compleja. En R. Grompone (ed.), Incertidumbre y distancias: el controvertido protagonismo del Estado en el Perú (pp. 175-206). Lima: Instituto de Estudios Peruanos. 
Dourojeanni, M. (2013). Loreto sostenible al 2021. Lima: Derecho, Ambiente y Recursos Naturales.

Dourojeanni, M. (12 de junio de 2017). Belaúnde en la Amazonía. Centro Amazónico de Antropología y Aplicación Práctica. Recuperado de http://www.caaap.org.pe/ website/2017/06/12/belaunde-en-la-amazonia-por-marc-j-dourojeanni/

Egerlid, J. (2015). Governing Indigenous territories in the Peruvian Amazon: placing people or forest first? (tesis de maestría). Swedish University of Agricultural Sciences, Uppsala, Suecia.

Evans, P.(1996). ElEstado como problemay solución. Desarrollo Económico, 35(140), 529-559. https://doi.org/10.2307/3467372

Garay, C. (2016). Social Policy Expansion in Latin America. Cambridge: Cambridge University Press. https://doi.org/10.1017/9781316585405

Gobierno Regional de San Martín (2008). Plan de Desarrollo Concertado de la Región de San Martín 2008-2015. San Martín: Gobierno Regional de San Martín.

Gómez, R. (2019). Gestión de los recursos naturales: retos al 2030. En F. Portocarrero y A. Vergara (eds.), Aproximaciones al Perú del siglo XXI desde las ciencias sociales. Lima: Fondo Editorial de la Universidad del Pacífico.

Grindle, M. (2004). Despite the Odds. The Contentious Polities of Education Reform. Princeton, NJ: Princeton University Press. https://doi.org/10.1515/9780691186818

Grindle, M. (2009). La brecha de la implementación. En F. Mariñez y V. Garza (eds.), Política pública y democracia en América Latina. Del análisis a la implementación (pp. 33-53). México D.F: Editorial Miguel Ángel Porrúa.

Ha, Y. y Kang, M. (2011). Creating a Capable Bureaucracy with Loyalists. The Internal Dynamics of the South Korean Development State, 1948-1979. Comparative Political Studies, 44(1), 78-108. https://doi.org/10.1177/0010414010381075

Haas, P. (1992). Introduction: Epistemic Communities and International Policy Coordination. International Organization, 46(1), 1-35. https://doi.org/10.1017/ S0020818300001442

Holland, A. (2017). Forbearance as redistribution: the politics of informal Welfare in Latin America. Cambridge, R.U.: Cambridge University Press. https://doi. org/10.1017/9781316795613

Kaulard,A. (2020). Sinergias entre el Estado y la sociedad: la política económica alternativa del Gobierno Regional de San Martín y sus «tigres y tigresas». Debates en Sociología, 47.

Levitsky, S. y Murillo, V. M. (2014). Building Institutions on Weak Foundations: Lessons from Latin America. En D. Brinks, M. Leiras y S. Mainwaring (eds.), Reflections on Uneven Democracies: The Legacy of Guillermo O'Donnell (pp. 189-213). Baltimore, MD: Johns Hopkins University Press.

McAllister, L. K. (2008). Making law: Environmental protection and legal institutions in Brazil. Stanford, CA: Stanford University Press. https://doi.org/10.11126/ stanford/9780804758239.001.0001 
Mann, M. (1984). The Autonomous Power of the State: Its Origins, Mechanisms, and Results. European Journal of Sociology, 25(2), 185-213. https://doi.org/10.1017/ S0003975600004239

Manrique, H. (2015). Las bases históricas del milagro de San Martín: control territorial y estrategias estatales contra el narcotráfico y subversión (1980-1995). Politai: Revista de Ciencia Política, 11(2), 33-51.

Meléndez, C. (2004). ¿Una descentralización sin partidos? El primer año de gestión del APRA en el gobierno regional de San Martín (Documento de trabajo 128). Lima: Instituto de Estudios Peruanos.

Migdal, J., Kohli, A. y Shue, V. (1994). Introduction: developing a state in society perspective. En J. Migdal, A. Kohli y V. Shue (eds.), State Power and Social Forces. Domination and Transformation in the Third World (pp. 1-7). Cambridge: Cambridge University Press.https://doi.org/10.1017/CBO9781139174268

Moscoso, W. (2018). ¿Desarrollo hacia dónde?: el análisis de la coalición promotora del desarrollo alternativo en Tocache (tesis de licenciatura). Pontificia Universidad Católica del Perú.

Muñoz, P. (2018). El entusiasmo de los que no entusiasman: descentralización y competencia electoral en el Perú. Perú Hoy, (33), 93-107.

Muñoz, P., Monsalve, M., Guibert, Y., Guadalupe, C. y Torres, J. (2016). Élites regionales en el Perú en un contexto de boom fiscal: Arequipa, Cusco, Piura y San Martín (2000-2013). Lima: Fondo Editorial de la Universidad del Pacífico. https://doi. org/10.21678/978-9972-57-368-2

North, D. (1995). New Institutional Economics and Third World Development. En J. Harris, J. Hunter y L. Colin (eds.), The New Institutional Economics and Third World Development (pp. 17-27). Londres y Nueva York: Routledge. https://doi. org/10.4324/9780203444290.pt1

O’Donnell, G. (1993). On the State, Democratization and Some Conceptual Problems: A Latin American View with Some Postcommunist Countries. World Development, 21(8), 1355-1369.https://doi.org/10.1016/0305-750X(93)90048-E

Oxhorn, P. (setiembre, 1998). Social Inequality and the limits of citizenship in Latin America. Ponencia presentada en la Conferencia del Latin American Studies Association. The Palmer House Hilton Hotel, Chicago.

Panfichi, A. (2011). Contentious Representation and its Impact in Contemporary Peru. En J. Crabtree (ed.), The Paradoxes of Development: Economic Growth, Social Malaise and Ethnic/Regional Protest in Peru (pp. 89-104). Londres: University of London Press.

Paredes, M. y Manrique, H. (2016). Ideas of Modernization and Territorial Transformation in the Rise of Coca: The Case of the Upper Huallaga Valley, Peru. En P. Gootenberg y L. Dávalos (eds.), The Origins of Cocaine: Colonization and Failed Development in the Amazon Andes (pp. 1-10). Nueva York: Routledge.

Pierson, P. (1993). When Effect Becomes Cause: Policy Feedback and Political Change. World Politics, 45(4), 595-628. https://doi.org/10.2307/2950710

Pinedo, T. (ed.). (2009). CEPCO y la región San Martín, una historia en paralelo. Lima: Gama Gráfica. 
Rich, J. (2019). Making National Participatory Institutions Work: Bureaucrats, Activists, and AIDS Policy in Brazil. Latin American Politics and Society, 61(2), 45-67. https:// doi.org/10.1017/lap.2018.80

Rich, J., Mayka, L. y Montero, A. (2019). Introduction: The Politics of Participation in Latin America: New Actors and Institutions. Latin American Politics and Society, 61(2), 21-44. https://doi.org/10.1017/lap.2018.74

Slater, D. y Kim, D. (2014). Standoffish States: Nonliterate Leviathans in Southeast Asia. Trans-Regional and National Studies of Southeast Asia, 3(1), 25-44. https://doi. org/10.1017/trn.2014.14

Tenorio, A., Rodríguez, D. y Neira, E. (2002). La pequeña agroindustra en San Martín desde la experiencia de ITDG. Lima: Intermediate Technology Development Group.

Vergara, A. (2011). United by Discord, Divided by Consensus: National and Sub-national Articulation in Bolivia and Peru, 2000-2010. Journal of Politics in Latin America, 3(3), 65-93. https://doi.org/10.1177/1866802X1100300303

Zárate, P.(2003). La democracia lejos de Lima: descentralización y politica en el departamento de San Martín. Lima: IEP. 